\title{
Impact of flow and temperature on patient comfort during respiratory support by high- flow nasal cannula
}

Tommaso Mauri ${ }^{1,2+}$, Alessandro Galazzi ${ }^{1,2+}$, Filippo Binda ${ }^{2}$, Laura Masciopinto², Nadia Corcione ${ }^{2}$, Eleonora Carlesso ${ }^{1}$, Marta Lazzeri ${ }^{3}$, Elena Spinelli ${ }^{2}$, Daniela Tubiolo ${ }^{2}$, Carlo Alberto Volta ${ }^{3}$, Ileana Adamini ${ }^{1,2}$, Antonio Pesenti ${ }^{1,2^{*}}$ (D) and Giacomo Grasselli, ${ }^{1,2}$

\begin{abstract}
Background: The high-flow nasal cannula (HFNC) delivers up to $60 \mathrm{l} / \mathrm{min}$ of humidified air/oxygen blend at a temperature close to that of the human body. In this study, we tested whether higher temperature and flow decrease patient comfort. In more severe patients, instead, we hypothesized that higher flow might be associated with improved comfort.

Methods: A prospective, randomized, cross-over study was performed on 40 acute hypoxemic respiratory failure (AHRF) patients $\left(\mathrm{PaO}_{2} / \mathrm{FiO}_{2} \leq 300+\right.$ pulmonary infiltrates + exclusion of cardiogenic edema) supported by HFNC. The primary outcome was the assessment of patient comfort during HFNC delivery at increasing flow and temperature. Two flows (30 and $60 \mathrm{l} / \mathrm{min}$ ), each combined with two temperatures ( 31 and $37^{\circ} \mathrm{C}$ ), were randomly applied for 20 min (four steps per patient), leaving clinical $\mathrm{FiO}_{2}$ unchanged. Toward the end of each step, the following were recorded: comfort by Visual Numerical Scale ranging between 1 (extreme discomfort) and 5 (very comfortable), together with respiratory parameters. A subgroup of more severe patients was defined by clinical $\mathrm{FiO}_{2} \geq 45 \%$.

Results: Patient comfort was reported as significantly higher during steps at the lower temperature $\left(31^{\circ} \mathrm{C}\right)$ in comparison to $37^{\circ} \mathrm{C}$, with the HFNC set at both 30 and $60 \mathrm{l} / \mathrm{min}(p<0.0001)$. Higher flow, however, was not associated with poorer comfort.

In the subgroup of patients with clinical $\mathrm{FiO}_{2} \geq 45 \%$, both lower temperature $\left(31^{\circ} \mathrm{C}\right)$ and higher HFNC flow ( $60 \mathrm{l} / \mathrm{min})$ led to higher comfort $(p<0.01)$.

Conclusions: HFNC temperature seems to significantly impact the comfort of AHRF patients: for equal flow, lower temperature could be more comfortable. Higher flow does not decrease patient comfort; at variance, it improves comfort in the more severely hypoxemic patient.
\end{abstract}

Keywords: High-flow nasal oxygen, Spontaneous breathing, Acute hypoxemic respiratory failure, Patient comfort, Nursing

\footnotetext{
* Correspondence: antonio.pesenti@unimi.it

${ }^{\dagger}$ Equal contributors

${ }^{1}$ Anesthesia and Critical Care, Department of Pathophysiology and

Transplantation, University of Milan, Via F. Sforza 35, 20122 Milan, Italy

2Department of Anesthesia, Critical Care and Emergency, Fondazione IRCCS

Ca' Granda Ospedale Maggiore Policlinico, Via F. Sforza 35, 20122 Milan, Italy

Full list of author information is available at the end of the article
}

(c) The Author(s). 2018 Open Access This article is distributed under the terms of the Creative Commons Attribution 4.0 International License (http://creativecommons.org/licenses/by/4.0/), which permits unrestricted use, distribution, and reproduction in any medium, provided you give appropriate credit to the original author(s) and the source, provide a link to the Creative Commons license, and indicate if changes were made. The Creative Commons Public Domain Dedication waiver (http://creativecommons.org/publicdomain/zero/1.0/) applies to the data made available in this article, unless otherwise stated. 


\section{Background}

The high-flow nasal cannula (HFNC) is a new noninvasive, easy-to-use respiratory support for adult patients with acute hypoxemic respiratory failure (AHRF). The HFNC delivers 30-60 l/min of humidified air and oxygen blend at the desired $\mathrm{FiO}_{2}$ and temperature [1]

Several recent randomized clinical trials in patients with or at risk for AHRF described decreased need for invasive mechanical ventilation and improved survival by early application of HFNC compared to standard oxygen or non-invasive positive pressure ventilation (NIPPV) [2, 3]. The HFNC is associated with several beneficial physiologic effects, potentially promoting spontaneous breathing, avoiding patient exhaustion, and decreasing the risk of patient self-inflicted lung injury (P-SILI) [4-8].

Although most studies reported that application of the HFNC is associated with higher patient comfort in comparison to NIPPV $[2,3]$, none investigated the degree of comfort at different HFNC settings. Improved comfort might be a strong clinical endpoint per se $[9,10]$ and useful to guide optimal HFNC settings, which are still debated. Previous clinical studies used highly heterogeneous criteria to set flow and temperature [11-15], and a study from our group described that physiologic effects of HFNC in AHRF patients might be maximized by different personalized flow rates rather than simply by the highest value [8], but no study investigated the effects of different temperature settings (with highest value commonly considered as optimal).

In this collaborative project, nurses assessed comfort during HFNC at increasing flow and temperature in AHRF patients. Our hypothesis was that higher flow and temperature might reduce comfort. We also planned a subanalysis to describe whether, in the subgroup of more severe patients clinically requiring higher inspiratory oxygen fraction $\left(\mathrm{FiO}_{2}\right)$, higher flow could result in improved comfort. The rationale was that higher HFNC flow more effectively corrects hypoxia and copes with elevated inspiratory effort $[7,8]$, potentially tampering the neural drive and improving comfort.

\section{Methods}

\section{Study population}

Non-intubated AHRF patients admitted to the intensive care unit (ICU) of the Fondazione IRCCS Ca' Granda Ospedale Maggiore Policlinico, Milan, Italy were included. Inclusion criteria were: new/worsening respiratory symptoms (e.g., dyspnea) following a known clinical insult (e.g., pneumonia) within 1 week; $\mathrm{PaO}_{2} / \mathrm{FiO}_{2} \leq 300$ despite additional oxygen as per clinical decision; and evidence of pulmonary infiltrates on chest X-ray or CT scan.
Exclusion criteria were: age $<18$ years; tracheostomy; hemodynamic instability (hypotension with mean arterial pressure $<60 \mathrm{mmHg}$ despite adequate volume resuscitation and vasoactive drugs); AHRF only due to cardiac failure; severe chronic obstructive pulmonary disease (i.e., documented stage IV or patients prescribed with home oxygen); and altered mental status.

The Fondazione IRCCS Ca' Granda Ethical Committee approved the study (reference 193_2017), and informed consent was obtained from each patient according to local regulations. Four ICU nurses (AG, FB, LM, and IA) independently performed the enrolment, study protocol, and data collection. Part of the data reported here has been presented in the form of an abstract awarded with the Nurses and Allied Healthcare Professionals Award of the European Society of Intensive Care Medicine (ESICM Congress, Wien, Austria, October 2017).

\section{Demographics and clinical severity}

At enrolment, the participants' age, sex, presence of bilateral infiltrates, Sepsis-related Organ Failure Assessment (SOFA) score, AHRF etiology, $\mathrm{PaO}_{2} / \mathrm{FiO}_{2}$ ratio, Simplified Acute Physiology Score (SAPS) II at ICU admission, and body mass index (BMI) were collected.

\section{Continuous monitoring}

Three-lead electrocardiogram, peripheral arterial oxygen saturation, and invasive arterial pressure were monitored during the whole study protocol.

\section{Study protocol}

Patients were nonsedated and kept in a semirecumbent position in a calm environment. Each patient underwent, in random order, four 20-min steps:

1. Gas flow $30 \mathrm{l} / \mathrm{min}$ and temperature $31^{\circ} \mathrm{C}$ (HF30-T31).

2. Gas flow $60 \mathrm{l} / \mathrm{min}$ and temperature $31^{\circ} \mathrm{C}$ (HF60-T31).

3. Gas flow $30 \mathrm{l} / \mathrm{min}$ and temperature $37^{\circ} \mathrm{C}$ (HF30-T37).

4. Gas flow $60 \mathrm{l} / \mathrm{min}$ and temperature $37^{\circ} \mathrm{C}$ (HF60-T37).

The HFNC was inserted through specific medium/large nasal prongs (Fisher \& Paykel Healthcare, Auckland, New Zealand) to fit the nares size. The attending physician clinically chose the $\mathrm{FiO}_{2}$ before enrolment to target peripheral saturation of $92-98 \%$ on pulse oximetry. $\mathrm{FiO}_{2}$ was continuously measured by a dedicated system $\left(\mathrm{AIRVO}^{\mathrm{sm}} 2\right.$; Fisher \& Paykel Healthcare, Auckland, New Zealand) connected to the HFNC and kept constant during all phases by adjusting the additional oxygen wall supply. The system can deliver airflows between 30 and $60 \mathrm{l} / \mathrm{min}$ with set $\mathrm{FiO}_{2}$ between 0.21 and 1.0. To identify the subgroup of more severe patients, a threshold for clinically selected $\mathrm{FiO}_{2} \geq 45 \%$ was chosen, as this represented a viable compromise between the need for excluding less severe 
patients (i.e., those left at $\mathrm{FiO}_{2} \leq 40 \%$ by the attending physician) [16] and assuring adequate subgroup numerosity.

\section{Measures}

Toward the end of each study phase, we collected data for oxygen saturation, $\mathrm{FiO}_{2}$, systolic and diastolic arterial pressure, heart rate, Borg dyspnea score, respiratory rate, and comfort score by Visual Numerical Scale (VNS) ranging between 1 (extreme discomfort) and 5 (very comfortable). In fact, the VNS is commonly used to assess comfort in the clinical environment [17], and has already been used in larger clinical studies on HFNC (e.g., FLORALI study [2]).

\section{Statistical analysis}

The enrolment of 40 patients was planned (study power $=0.8, \alpha=0.05$ ) based on a clinically meaningful difference of $2.0 \pm 1.5$ points in patient comfort between HF30-T31 vs HF60-T37 [1]. Numerosity seemed reasonable also to obtain sufficiently large subgroups.

Data are expressed as mean \pm standard deviation or median (interquartile range (IQR)).

Differences between variables measured during the four study phases (HF30-T31 vs HF60-T31 vs HF30-T37 vs HF60-T37) in the whole population and in the two $\mathrm{FiO}_{2}$ range subgroups (fixed effects) were tested by a generalized linear mixed model (GLIMMIX) with a carryover effect. Post hoc Bonferroni or Tukey multiple comparison tests were performed. The carryover variable was the combination of flow and temperature applied in the preceding phase to exclude influence from the random sequence.

For comparisons of baseline variables between groups defined by a $\mathrm{FiO}_{2}$ threshold of $45 \%$, a paired $t$ test or Wilcoxon's signed rank test was used as appropriate. Baseline categorical variables between the two subgroups were compared by chi-square test.

The study phase associated with the highest VNS value for comfort was indicated as "best comfort settings" for that individual patient, while the one with the lowest value was indicated as "worst comfort settings".

$p<0.05$ (two-tailed) was considered statistically significant. The statistical software used was SigmaPlot 12.0 (Systat Software Inc., San Jose, CA USA) and SAS 9.2 (SAS Institute Inc., Cary, NC, USA).

\section{Results}

\section{Study population}

Forty patients were enrolled: mean age was $57 \pm 15$ years and 16 were female (40\%). The clinical condition was quite severe, with SAPS II of $36 \pm 9$ and median SOFA score of 4 (IQR 4-6). Pulmonary infiltrates were bilateral in 28 cases (70\%). AHRF was of pulmonary origin in $48 \%$ and of infectious etiology in $56 \%$ of the patients.
The main characteristics of the study population are presented in Table 1.

\section{Effects of flow and temperature on comfort in the study population}

Patient comfort was significantly higher during steps performed at the lower temperature (HF30-T31 and HF60-T31) in comparison with the higher temperature (HF30-T37 and HF60-T37) $(p<0.0001$ by GLIMMIX; see Fig. 1a legend for post hoc comparisons). On the contrary, comfort was not affected by flow values (Fig. 1a).

\section{Effects of flow and temperature on comfort in patients with $\mathrm{FiO}_{2} \geq 45 \%$}

A comparison of baseline characteristics in the subgroups of patients requiring $\mathrm{FiO}_{2}<45 \%$ vs $\mathrm{FiO}_{2} \geq 45 \%$ [16] is reported in Table 1. Significant baseline differences were reported for $\mathrm{FiO}_{2}, \mathrm{SpO}_{2} / \mathrm{FiO}_{2}$, respiratory rate, and Borg score with worse values in the more hypoxemic patients, and these might confirm accurate stratification of AHRF severity by the chosen $\mathrm{FiO}_{2}$ threshold.

In both subgroups, lower temperature (HF30-T31 and HF60-T31 vs HF30-T37 and HF60-T37) was still associated with higher comfort, but, at variance from the whole population and the other subgroup, higher HFNC flow significantly improved comfort in patients with higher $\mathrm{FiO}_{2}$ (HF60-T31 and HF60-T37 vs HF30-T31 and HF30-T37, $p<0.001$ by GLIMMIX; see figure legend for post hoc comparisons) (Fig. 1b).

\section{Optimum HFNC settings for patient comfort}

In the whole population, on average, comfort during HFNC was elevated in all study phases (median 3 (IQR 2-4), mean $3.2 \pm 1.4$ ); at the patient level, fair to high comfort (i.e., $\geq 3$ ) was always achieved in at least one phase. Four patients (10\%) reached 3 as the maximum comfort level (two patients during HF30-T31, one patient during HF30-T37, one patient during HF60-T31, no patient during HF60-T37), 11 (27.5\%) reached a level of 4 (four patients during HF30-T31, five patients during HF30-T37, one patient during HF60-T31, one patient during HF60-T37), and 25 (62.5\%) reached a maximum score of 5 (nine patients during HF30-T31, nine patients during HF30-T37, one patient during HF60-T31, six patients during HF60-T37).

"Best comfort settings" were HF30-T31 in 15 patients (37.5\%), HF30-T37 in 15 patients (37.5\%), HF60-T31 in three patients $(7.5 \%)$, and HF60-T37 in seven patients $(17.5 \%)(p=0.01) \quad$ (Fig. 2a). Conversely, "worse comfort settings" were HF30-T31 in four patients (10\%), HF60-T31 in two patients (5\%), HF30-T37 in 23 patients (57.5\%), and HF60-T37 in 11 patients (27.5\%) $(p<0.0001)$ (Fig. 2b). 
Table 1 Baseline characteristics of the study population

\begin{tabular}{|c|c|c|c|c|}
\hline Characteristic & $\begin{array}{l}\text { Overall population } \\
(N=40)\end{array}$ & $\begin{array}{l}\mathrm{FiO}_{2}<45 \% \\
(\mathrm{~N}=24)\end{array}$ & $\begin{array}{l}\mathrm{FiO}_{2} \geq 45 \% \\
(\mathrm{~N}=16)\end{array}$ & $\begin{array}{l}p \text { value, } \mathrm{FiO}_{2}<45 \% \\
\text { vs } \mathrm{FiO}_{2} \geq 45 \%\end{array}$ \\
\hline Age (years) & $57 \pm 15$ & $55 \pm 14$ & $62 \pm 16$ & 0.17 \\
\hline Female sex, $n(\%)$ & $16(40 \%)$ & $8(33.3 \%)$ & $8(50 \%)$ & 0.29 \\
\hline Monolateral/bilateral infiltrates, $n$ (\%) & $12(30 \%) / 28(70 \%)$ & $8(33 \%) / 16(67 \%)$ & $4(25 \%) / 12(75 \%)$ & 0.57 \\
\hline SOFA score & $4(3-6)$ & $3.5(3-6)$ & $4(3-6)$ & 0.89 \\
\hline $\begin{array}{l}\text { Pulmonary/extrapulmonary } \\
\text { cause of ARDS, } n(\%)\end{array}$ & $19(48 \%) / 21(53 \%)$ & $11(46 \%) / 13(54 \%)$ & $8(50 \%) / 8(50 \%)$ & 0.80 \\
\hline $\begin{array}{l}\text { Infectious/non-infectious cause } \\
\text { of ARDS, } n(\%)\end{array}$ & $22(56 \%) / 18(45 \%)$ & $14(58 \%) / 10(42 \%)$ & $8(50 \%) / 8(50 \%)$ & 0.60 \\
\hline $\mathrm{FiO}_{2}$ & $40(40-50)$ & $40(40-40)$ & $50(50-60)$ & $<0.0001^{*}$ \\
\hline Respiratory rate (bpm) & $22(18-24)$ & $20(18-24)$ & $24(20-30)$ & $0.05^{*}$ \\
\hline Borg scale & $2(1-3)$ & $1(0-3)$ & $3(2-4)$ & $0.02^{*}$ \\
\hline Comfort & $4(3-5)$ & $4(3-5)$ & $4(3-5)$ & 0.81 \\
\hline $\mathrm{SpO}_{2} / \mathrm{FiO}_{2}$ & $241(196-249)$ & $248(243-250)$ & $192(161-199)$ & $<0.0001^{*}$ \\
\hline SAPS $\|$ & $36 \pm 9$ & $38 \pm 8$ & $35 \pm 11$ & 0.35 \\
\hline
\end{tabular}

Normally distributed variables reported as mean \pm standard deviation, non-normal variables reported as median (interquartile range). $p$ values obtained by $t$ test, Wilcoxon rank-sum test, or chi-square test as appropriate

ARDS acute respiratory distress syndrome, $\mathrm{FiO}_{2}$ inspired oxygen fraction, SAPS Simplified Acute Physiology Score, SOFA Sepsis-related Organ Failure Assessment,

$\mathrm{SpO}_{2}$ peripheral oxygen saturation

*Data significant at $p<0.05$

\section{Effects of flow and temperature on vital signs and respiratory pattern}

Among the collected variables, higher flow improved oxygenation $(p<0.0001$ by GLIMMIX; see table legend for post hoc comparisons), while higher temperature was associated with increased heart rate $(p=0.021$ by GLIMMIX; see table legend for post hoc comparisons) (Table 2). However, from a clinical point of view, changes in vital signs induced by different HFNC settings were only marginally relevant.

\section{Discussion}

The main findings of our study can be summarized as follows: in AHRF patients undergoing HFNC, comfort assessed by Visual Numeric Scale was higher at lower temperature, regardless of flow rate; in the subgroup of
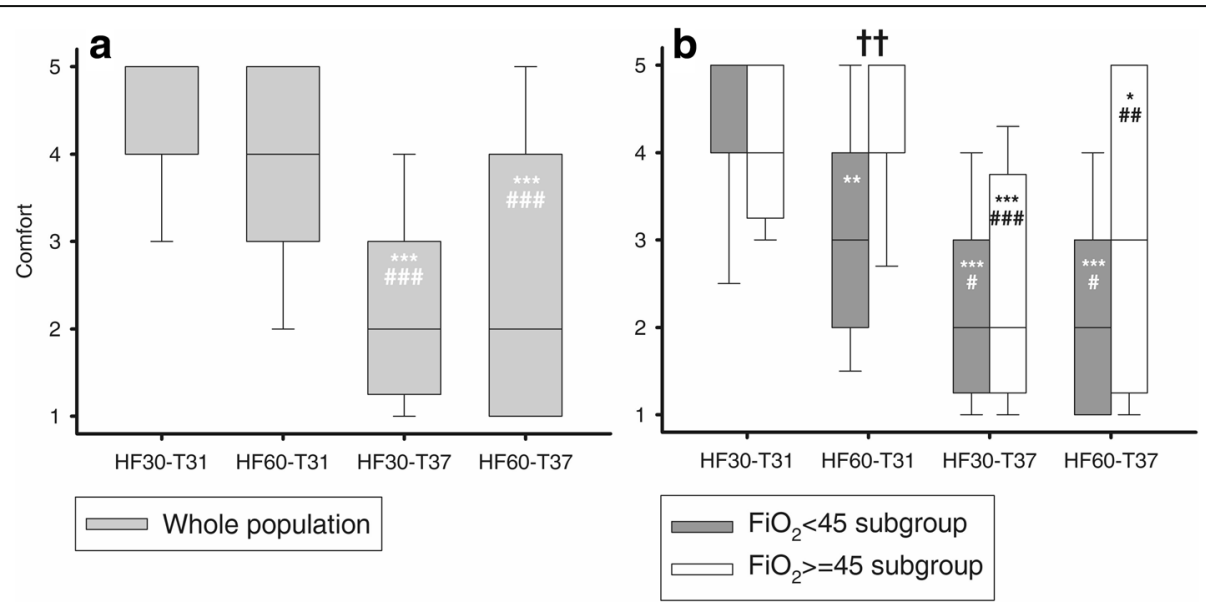

Fig. 1 Impact of temperature and flow on patient comfort. Values reported as median with $10^{\circ}, 25^{\circ}, 75^{\circ}$, and $90^{\circ}$ percentiles as vertical boxes with error bars. a Whole population, overall $p<0.0001$ (GLIMMIX). Post hoc analysis: ${ }^{* *} p<0.001$ vs HF30-T31, \#\#\#p $<0.001$ vs HF60-T31. b Subgroup analyses: grey boxes represent $\mathrm{FiO}_{2}<45 \%$ subgroup, while white boxes represent $\mathrm{FiO}_{2} \geq 45 \%$ subgroup. $p$ values from GLIMMIX analysis: treatment effect $p<0.001 ; \mathrm{FiO}_{2}$ effect $=0.055$; interaction $=0.035$. Post hoc analysis: ${ }^{*} p<0.05$ vs HF30-T31; ${ }^{* *} p<0.01$ vs HF30-T31; ${ }^{* * *} p<0.001$ vs HF30-T31; $\# p<0.05$ vs HF60-T31; \#\#p 0.01 vs HF60-T31; \#\#\#p $<0.001$ vs HF60-T31; $+\uparrow p<0.01$ vs $\mathrm{FiO}_{2}<45 \%$ subgroup (same step). FiO ${ }_{2}$ inspired oxygen fraction, HF30-T31 gas flow $30 \mathrm{l} / \mathrm{min}$ and temperature $31{ }^{\circ} \mathrm{C}$, HF60-T31 gas flow $60 \mathrm{l} / \mathrm{min}$ and temperature $31{ }^{\circ} \mathrm{C}$, HF30-T37 gas flow $30 \mathrm{l} / \mathrm{min}$ and temperature $37^{\circ} \mathrm{C}$, HF60-T37 gas flow $60 \mathrm{l} / \mathrm{min}$ and temperature $37^{\circ} \mathrm{C}$ 


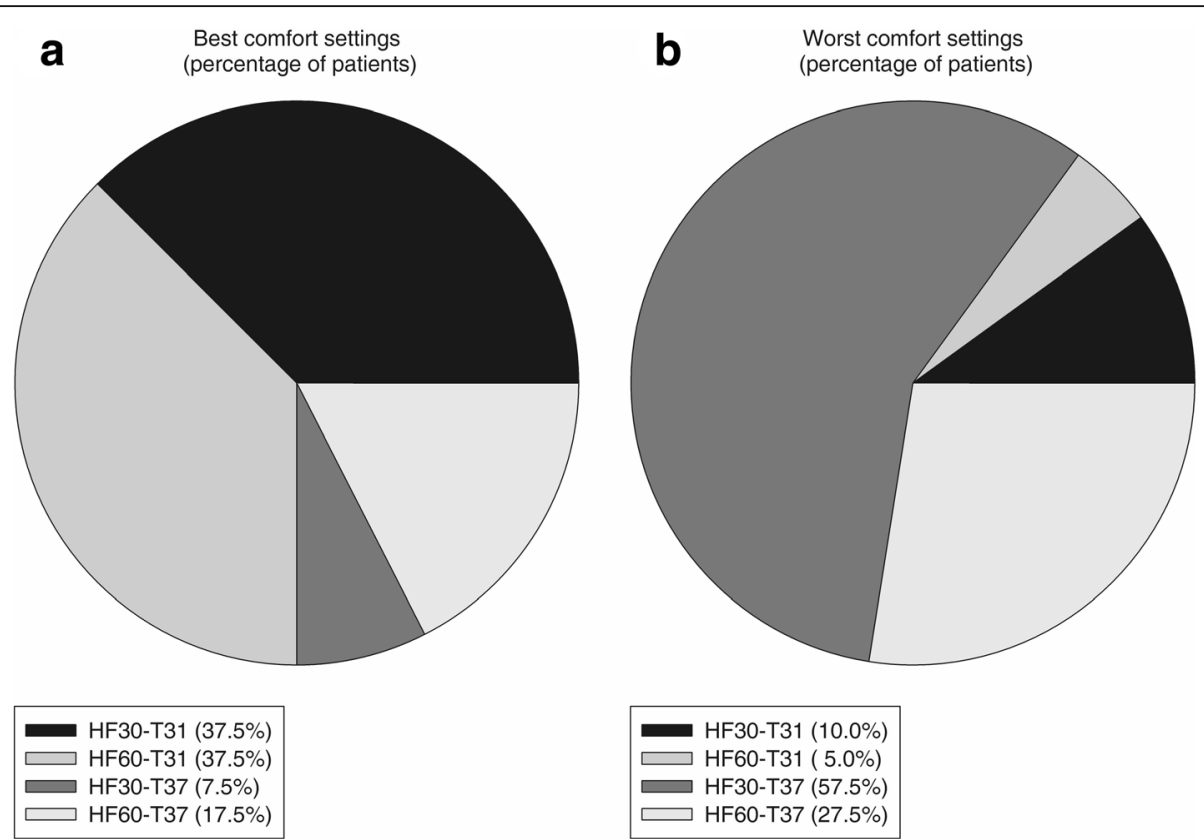

Fig. 2 Best and worst comfort. Distribution of "best comfort settings" (a) and "worst comfort settings" (b) expressed as percentage of patients reporting highest or lowest comfort value in that particular study phase (see text for detailed description). HF30-T31 gas flow $30 \mathrm{l} / \mathrm{min}$ and temperature $31{ }^{\circ} \mathrm{C}$, HF60-T31 gas flow $60 \mathrm{l} / \mathrm{min}$ and temperature $31{ }^{\circ} \mathrm{C}$, HF30-T37 gas flow $30 \mathrm{l} / \mathrm{min}$ and temperature $37^{\circ} \mathrm{C}$, HF60-T37 gas flow $60 \mathrm{l} / \mathrm{min}$ and temperature $37^{\circ} \mathrm{C}$

more severe patients (i.e., those with clinical $\mathrm{FiO}_{2} \geq 45 \%$ ), both lower temperature and higher flow were associated with improved comfort; and HFNC settings associated with best and worst comfort presented large variability at the individual patient level.

In humans, the alveolar membrane is a dead-ended structure reached only by isothermal $(100 \%$ relative humidity and $44 \mathrm{mg} / \mathrm{l} \mathrm{H}_{2} \mathrm{O}$ absolute humidity) and body-warm $\left(37^{\circ} \mathrm{C}\right)$ air. Thus, the respiratory support respecting this condition the most should be associated with increased comfort and, potentially, with decreased unphysiologic mechanisms (e.g., inflammation, reduced immunity, altered airway patency) [18-23]. The HFNC, unlike cool and anhydrous conventional oxygen therapy, can deliver to the alveoli an air-oxygen moisturized and heated blend. In this study, we measured patient comfort during various HFNC settings, as comfort could represent a balanced synthesis of various physiologic mechanisms, potentially being a patient-level outcome per se $[9,10]$. Previous physiologic studies in patients undergoing non-invasive respiratory support assessed comfort by the same method as used in this study (i.e., VNS) [24, 25]. Comfort during non-invasive support could be particularly relevant for improving tolerance. Indeed, an ongoing

Table 2 Comparison of vital signs during each study phase (see text for details)

\begin{tabular}{|c|c|c|c|c|c|}
\hline Variable & $\begin{array}{l}\text { HF30-T31 } \\
(N=40)\end{array}$ & $\begin{array}{l}\text { HF60-T31 } \\
(N=40)\end{array}$ & $\begin{array}{l}\text { HF30-T37 } \\
(N=40)\end{array}$ & $\begin{array}{l}\text { HF60-T37 } \\
(N=40)\end{array}$ & $\begin{array}{l}p \text { value, } \\
\text { GLIMMIX }\end{array}$ \\
\hline Systolic arterial pressure $(\mathrm{mmHg})$ & $122(112-136)$ & $121(109-135)$ & $124(109-138)$ & $120(111-135)$ & 0.854 \\
\hline Diastolic arterial pressure $(\mathrm{mmHg})$ & $64(59-70)$ & $63(56-70)$ & $65(53-70)$ & $65(60-70)$ & 0.731 \\
\hline Heart rate (bpm) & $88 \pm 15$ & $87 \pm 15$ & $90 \pm 15^{\ddagger}$ & $89 \pm 15$ & $0.02^{* *}$ \\
\hline $\mathrm{SpO}_{2}(\%)$ & $96(94-99)$ & $98(96-100)^{\dagger}$ & $96(95-99)^{\S}$ & $98(96-99)^{+\|}$ & $<0.0001^{* *}$ \\
\hline Respiratory rate (bpm) & $22(18-29)$ & $22(19-25)$ & $23(19-29)$ & $23(19-26)$ & 0.174 \\
\hline Borg scale & $3(2-5)$ & $3(1-5)$ & $4(2-5)$ & $3(2-5)$ & 0.557 \\
\hline $\mathrm{SpO}_{2} / \mathrm{FiO}_{2}$ & $238(192-246)$ & $240(196-248)^{\dagger}$ & $240(190-248)^{\ddagger}$ & $240(196-248)^{*}$ & $<0.001^{* *}$ \\
\hline
\end{tabular}

$\mathrm{FiO}_{2}$ inspired oxygen fraction, GLIMMIX generalized linear mixed model, HF30-T31 gas flow $30 \mathrm{l} / \mathrm{min}$ and temperature $31{ }^{\circ} \mathrm{C}, \mathrm{HF} 60-\mathrm{T} 31 \mathrm{gas}$ flow $60 \mathrm{l} / \mathrm{min}$ and temperature $31{ }^{\circ} \mathrm{C}, \mathrm{HF} 30-\mathrm{T} 37$ gas flow $30 \mathrm{l} / \mathrm{min}$ and temperature $37^{\circ} \mathrm{C}, \mathrm{HF} 60-\mathrm{T} 37$ gas flow $60 \mathrm{l} / \mathrm{min}$ and temperature $37^{\circ} \mathrm{C}$, SpO $\mathrm{O}_{2}$ peripheral oxygen saturation Post hoc comparisons: ${ }^{*} p<0.01$ vs HF30-T31; ${ }^{\dagger} p<0.001$ vs HF30-T31; ${ }^{*} p<0.05$ vs HF60-T31; ${ }^{5} p<0.001$ vs HF60-T31; $\|^{\prime} p<0.001$ vs HF30-T37

**Data significant at $p<0.05$ 
randomized controlled trial on a musical intervention in ICU patients on non-invasive ventilation has comfort evaluated by VNS as a primary endpoint [26]. Finally, a recent post hoc analysis of the FLORALI study identified poor comfort as the only predictor of intubation in patients on HFNC within $1 \mathrm{~h}$ from the start, thus suggesting a link between comfort and improved hard clinical outcomes [27]. Interestingly, in all of these studies [1, 24, 25, 27] dyspnea was independently assessed by the Borg scale as we did. Relief of dyspnea is only one component of improved comfort, and discomfort can still be present at relatively low dyspnea scores, its determinants being wider and more holistic (e.g., including also physiologic and sensorial factors).

Our findings that comfort is higher at T31 than at T37 independently from the set flow rate might suggest that a series of negative physiologic (e.g., unbalanced water retention) and psychosomatic (e.g., excessive heating of the nostrils) signals might prevail over the advantage of maximum humidity. However, since during use of the HFNC the heating and moisturizing function of the upper airways is preserved, inspired gases at $31{ }^{\circ} \mathrm{C}$ with full humidification should already prevent airway dryness and associated lesions. Hence, starting the HFNC at lower temperature (and eventually increasing it with time) may be a reasonable clinical approach to exploit the positive clinical outcomes deriving from higher tolerance, longer application of the non-invasive support, and improved comfort per se.

Equally complex are the effects of flow rate on comfort, due to the potential interplay between mechanical, chemical, and psychological stimuli [28, 29]. Previous studies showed that higher HFNC flow allows a more reliable correspondence between set and alveolar $\mathrm{FiO}_{2}$ and obtains higher PEEP effects $[8,14]$. Our finding that, in the whole population, comfort at lower flow did not differ significantly from higher flow might indicate either a low patient severity (with relatively low inspiratory flow) or a prevalence of biochemical stimuli and sensation of airway dryness over those deriving from more effective mechanical displacement of the respiratory system.

In more severe patients clinically requiring higher $\mathrm{FiO}_{2}$ levels, better comfort was reached at higher flow rates $(60 \mathrm{l} / \mathrm{min})$ and this might suggest that more effective correction of hypoxemia and/or improved lung mechanics $[7,8]$ might have prevailed at higher flow as determinants of comfort. As a clinical reference, higher flows could be recommended in more severe patients requiring higher $\mathrm{FiO}_{2}$ as this could couple improved physiology $[8,14]$ with higher comfort.

The finding that the "best and worst comfort" was reached at different combinations of flow and temperature in the individual patient might suggest that HFNC is yet another ICU treatment that could benefit from personalized rather than average standardized settings [30]. AHRF is a highly heterogeneous syndrome with regards to etiology (e.g., trauma vs infection), lung mechanics (higher vs lower compliance), and systemic involvement (number of organ failures) [31] and it seems physiologically sound that the same "average" treatment should not be applied to all patients. As in the acute respiratory distress syndrome, where PEEP, tidal volume, fluid management, and extracorporeal $\mathrm{CO}_{2}$ removal might have largely different effects based on patient subphenotype [32-35], HFNC settings might need to be applied in an individualized fashion. To this end, our findings might suggest that comfort could be the bedside endpoint to personalize HFNC titration, but this should be validated in larger studies.

Our study has some limitations. First, its primary aim was to assess patient comfort, which might be viewed only as a psychologic secondary outcome. However, patients experience a sense of relief when their physical and psychologic comfort needs are met $[9,10]$, and comfort might be an accurate multifaceted method to estimate and improve the effectiveness of non-invasive respiratory support [24-26]. Moreover, pilot data suggest a link between poor comfort early during application of HFNC and subsequent intubation [27]. Second, the results derive from a short-time observation $(20 \mathrm{~min}$ for each phase) and they should be confirmed by more extensive surveillance. Third, we tried to precisely define AHRF but our population was likely highly heterogeneous in terms of etiology, inflammation activation, and derangement of respiratory mechanics. Fourth, the more severe subgroup was identified by clinically set $\mathrm{FiO}_{2}$, which might have some individual discretion. However, clinical $\mathrm{FiO}_{2}$ was somehow standardized to obtain acceptable $\mathrm{SpO}_{2}$ and could also reflect a more global evaluation of the patient's severity by the attending physician; a previous study showed high discriminatory power of $\mathrm{FiO}_{2}$ for ARDS severity [16]; and objective assessment of AHRF severity in non-intubated patients is challenging as accepted measures such as intrapulmonary shunt or respiratory system compliance are lacking. Fifth, we did not explore midway settings but only extremes of temperature and flow; for this reason, it is difficult to understand whether the correlation between comfort and temperature is linear or characterized by a steep threshold change.

\section{Conclusions}

Set temperature during use of the HFNC seems to significantly impact the comfort of AHRF patients: for equal flow, lower temperature could be more comfortable. Higher flow does not decrease comfort: on the contrary, in the subgroup of more severely hypoxemic patients, higher flow improves comfort. At the individual 
patient level, high variability exists in the settings associated with highest and lowest comfort, and the HFNC might need personalized titration. To this end, patient comfort might already represent a smart and crafty indicator to guide settings of non-invasive respiratory support by HFNC.

\begin{abstract}
Abbreviations
AHRF: Acute hypoxemic respiratory failure; BMI: Body mass index $\mathrm{CO}_{2}$ : Carbon dioxide; $\mathrm{CT}$ : Computed tomography; $\mathrm{FiO}_{2}$ : Inspired oxygen fraction; GLIMMIX: Generalized linear mixed model; HF30-T31: Gas flow 30 I/min and temperature $31{ }^{\circ} \mathrm{C}$; HF30-T37: Gas flow $30 \mathrm{l} / \mathrm{min}$ and temperature $37^{\circ} \mathrm{C}$; HF60-T31: Gas flow $60 \mathrm{I} / \mathrm{min}$ and temperature $31^{\circ} \mathrm{C}$; HF60-T37: Gas flow $60 \mathrm{I} / \mathrm{min}$ and temperature $37^{\circ} \mathrm{C}$; HFNC: High-flow nasal cannula; ICU: Intensive care unit: IQR: Interquartile range; NIPPV: Non-invasive positive pressure ventilation; $\mathrm{PaO}_{2}$ : Partial oxygen pressure; PEEP: Positive end expiratory pressure; P-SILI: Patient self-inflicted lung injury; SAPS: Simplified Acute Physiology Score; SOFA: Sepsis-related Organ Failure Assessment
\end{abstract}

\section{Funding}

The present study was supported in part by institutional funding (Ricerca corrente 2018-Rimozione extracorporeal di anidride carbonica $\left(\mathrm{CO}_{2}\right)$ e modulazione della ventilazione spontanea in pazienti con insufficienza respiratoria acuta (sindrome da distress respiratorio, ARDS) e acuta su cronico (broncopneumopatia cronico ostruttiva, COPD)) of the Department of Anesthesia, Critical Care and Emergency, Fondazione IRCCS Ca' Granda Ospedale Maggiore Policlinico, Milan, Italy.

\section{Availability of data and materials}

The datasets used and/or analyzed during the present study are available from the corresponding author on reasonable request.

\section{Authors' contributions}

$T M, A G, F B, L M, I A, G G$, and AP provided substantial contributions to the conception or design of the work. TM, AG, FB, LM, EC, ML, ES, IA, GG, and AP contributed to acquisition, analysis, or interpretation of data for the work. $T M, N C, E C, E S, D T, C A V, I A, A P$, and GG contributed to drafting the work or revising it critically for important intellectual content. All authors approved the final version of the manuscript submitted for publication. TM and AP provide accountability for all aspects of the work in ensuring that questions related to the accuracy or integrity of any part of the work are appropriately investigated and resolved.

\section{Ethics approval and consent to participate}

The Fondazione Ethical Committee approved the study (193_2017), and informed consent was obtained from each patient according to local regulations.

\section{Competing interests}

AP reports personal fees from Maquet, Novalung/Xenios, Baxter, and Boehringer Ingelheim outside the submitted work. TM reports personal fees from Fisher and Paykel outside the submitted work. The remaining authors declare that they have no competing interests.

\section{Publisher's Note}

Springer Nature remains neutral with regard to jurisdictional claims in published maps and institutional affiliations.

\footnotetext{
Author details

${ }^{1}$ Anesthesia and Critical Care, Department of Pathophysiology and Transplantation, University of Milan, Via F. Sforza 35, 20122 Milan, Italy. ${ }^{2}$ Department of Anesthesia, Critical Care and Emergency, Fondazione IRCCS Ca' Granda Ospedale Maggiore Policlinico, Via F. Sforza 35, 20122 Milan, Italy. ${ }^{3}$ Department of Morphology, Surgery and Experimental Medicine, Section of Anesthesia and Intensive Care, University of Ferrara, Ferrara, Italy.
}

Received: 9 January 2018 Accepted: 13 April 2018

Published online: 09 May 2018

\section{References}

1. Hernandez G, Roca O, Colinas L. High-flow nasal cannula support therapy: new insights and improving performance. Crit Care. 2017;21(1):62

2. Frat JP, Thille AW, Mercat A, Girault C, Ragot S, Perbet S, Prat G, Boulain T, Morawiec E, Cottereau A, et al. High-flow oxygen through nasal cannula in acute hypoxemic respiratory failure. N Engl J Med. 2015;372(23):2185-96.

3. Papazian L, Corley A, Hess D, Fraser JF, Frat JP, Guitton C, Jaber S, Maggiore SM, Nava S, Rello J, et al. Use of high-flow nasal cannula oxygenation in ICU adults: a narrative review. Intensive Care Med. 2016;42(9):1336-49.

4. Mauri T, Cambiaghi B, Spinelli E, Langer T, Grasselli G. Spontaneous breathing: a double-edged sword to handle with care. Ann Transl Med. 2017;5(14):292.

5. Mauri T, Grasselli G, Jaber S. Respiratory support after extubation: noninvasive ventilation or high-flow nasal cannula, as appropriate. Ann Intensive Care. 2017;7(1):52.

6. Delorme M, Bouchard PA, Simon M, Simard S, Lellouche F. Effects of high-flow nasal cannula on the work of breathing in patients recovering from acute respiratory failure. Crit Care Med. 2017;45(12):1981-8.

7. Mauri T, Turrini C, Eronia N, Grasselli G, Volta CA, Bellani G, Pesenti A. Physiologic effects of high-flow nasal cannula in acute hypoxemic respiratory failure. Am J Respir Crit Care Med. 2017;195(9):1207-15.

8. Mauri T, Alban L, Turrini C, Cambiaghi B, Carlesso E, Taccone P, Bottino N, Lissoni A, Spadaro S, Volta CA, et al. Optimum support by high-flow nasal cannula in acute hypoxemic respiratory failure: effects of increasing flow rates. Intensive Care Med. 2017:43(10):1453-63.

9. Kolcaba K, Tilton C, Drouin C. Comfort Theory: a unifying framework to enhance the practice environment. J Nurs Adm. 2006;36(11):538-44.

10. Krinsky R, Murillo I, Johnson J. A practical application of Katharine Kolcaba's comfort theory to cardiac patients. Appl Nurs Res. 2014;27(2):147-50.

11. Azoulay E, Pickkers P, Soares M, Perner A, Rello J, Bauer PR, van de Louw A, Hemelaar $P$, Lemiale $V$, Taccone FS, et al. Acute hypoxemic respiratory failure in immunocompromised patients: the Efraim multinational prospective cohort study. Intensive Care Med. 2017;43(12):1808-19.

12. Hernandez G, Vaquero C, Colinas L, Cuena R, Gonzalez P, Canabal A, Sanchez S, Rodriguez ML, Villasclaras A, Fernandez R. Effect of postextubation high-flow nasal cannula vs noninvasive ventilation on reintubation and postextubation respiratory failure in high-risk patients: a randomized clinical trial. JAMA. 2016;316(15):1565-74.

13. Mundel T, Feng S, Tatkov S, Schneider H. Mechanisms of nasal high flow on ventilation during wakefulness and sleep. J Appl Physiol (1985). 2013;114(8):1058-65.

14. Parke RL, McGuinness SP. Pressures delivered by nasal high flow oxygen during all phases of the respiratory cycle. Respir Care. 2013;58(10):1621-4.

15. Pisani L, Fasano L, Corcione N, Comellini V, Musti MA, Brandao M, Bottone D, Calderini E, Navalesi P, Nava S. Change in pulmonary mechanics and the effect on breathing pattern of high flow oxygen therapy in stable hypercapnic COPD. Thorax. 2017;72(4):373-5.

16. Britos M, Smoot E, Liu KD, Thompson BT, Checkley W, Brower RG. National Institutes of Health Acute Respiratory Distress Syndrome Network I. The value of positive end-expiratory pressure and Fio(2) criteria in the definition of the acute respiratory distress syndrome. Crit Care Med. 2011;39(9):2025-30.

17. Wallace D, Cooper NR, Paulmann S, Fitzgerald PB, Russo R. Perceived comfort and blinding efficacy in randomised sham-controlled transcranial direct current stimulation (tDCS) trials at $2 \mathrm{~mA}$ in young and older healthy adults. PLoS One. 2016;11(2):e0149703.

18. Hernandez-Jimenez C, Garcia-Torrentera R, Olmos-Zuniga JR, Jasso-Victoria R, Gaxiola-Gaxiola MO, Baltazares-Lipp M, Gutierrez-Gonzalez LH. Respiratory mechanics and plasma levels of tumor necrosis factor alpha and interleukin 6 are affected by gas humidification during mechanical ventilation in dogs. PLoS One. 2014;9(7):e101952.

19. Foxman EF, Storer JA, Fitzgerald ME, Wasik BR, Hou L, Zhao H, Turner PE, Pyle AM, Iwasaki A. Temperature-dependent innate defense against the common cold virus limits viral replication at warm temperature in mouse airway cells. Proc Natl Acad Sci U S A. 2015;112(3):827-32.

20. Tseng CM, Chen YT, Ou SM, Hsiao YH, Li SY, Wang SJ, Yang AC, Chen TJ, Perng DW. The effect of cold temperature on increased exacerbation of chronic obstructive pulmonary disease: a nationwide study. PLoS One. 2013;8(3):e57066. 
21. Graff TD, Benson DW. Systemic and pulmonary changes with inhaled humid atmospheres: clinical application. Anesthesiology. 1969;30(2):199-207.

22. Sleigh MA, Blake JR, Liron N. The propulsion of mucus by cilia. Am Rev Respir Dis. 1988;137(3):726-41.

23. Williams R, Rankin N, Smith T, Galler D, Seakins P. Relationship between the humidity and temperature of inspired gas and the function of the airway mucosa. Crit Care Med. 1996;24(11):1920-9.

24. Stéphan F, Bérard L, Rézaiguia-Delclaux S, Amaru P, BiPOP Study Group. High-flow nasal cannula therapy versus intermittent noninvasive ventilation in obese subjects after cardiothoracic surgery. Respir Care. 2017;62(9):1193-202.

25. Longhini F, Pan C, Xie J, Cammarota G, Bruni A, Garofalo E, Yang Y, Navalesi P, Qiu $\mathrm{H}$. New setting of neurally adjusted ventilatory assist for noninvasive ventilation by facial mask: a physiologic study. Crit Care. 2017;21(1):170.

26. Messika J, Hajage D, Panneckoucke N, Villard S, Martin Y, Renard E, Blivet A, Reignier J, Maquigneau N, Stoclin A, et al. Effect of a musical intervention on tolerance and efficacy of non-invasive ventilation in the ICU: study protocol for a randomized controlled trial (MUSique pour l'Insuffisance Respiratoire Aigue—Mus-IRA). Trials. 2016;17(1):450.

27. Frat JP, Ragot S, Coudroy R, Constantin JM, Girault C, Prat G, Boulain T, Demoule A, Ricard JD, Razazi K, et al. Predictors of intubation in patients with acute hypoxemic respiratory failure treated with a noninvasive oxygenation strategy. Crit Care Med. 2018;46(2):208-15.

28. Manning HL, Molinary EJ, Leiter JC. Effect of inspiratory flow rate on respiratory sensation and pattern of breathing. Am J Respir Crit Care Med. 1995;151(3 Pt 1):751-7.

29. Schwartzstein RM, Simon PM, Weiss JW, Fend V, Weinberger SE. Breathlessness induced by dissociation between ventilation and chemical drive. Am Rev Respir Dis. 1989;139(5):1231-7.

30. Mauri T, Grasselli G, Pesenti A. Systematic assessment of advanced respiratory physiology: precision medicine entering real-life ICU? Crit Care. 2017;21(1):143

31. Gattinoni L, Tonetti T, Quintel M. Regional physiology of ARDS. Crit Care 2017;21(Suppl 3):312

32. Calfee CS, Delucchi K, Parsons PE, Thompson BT, Ware LB. Matthay MA; NHLBI ARDS Network. Subphenotypes in acute respiratory distress syndrome: latent class analysis of data from two randomised controlled trials. Lancet Respir Med. 2014;2(8):611-20.

33. Amato MB, Meade MO, Slutsky AS, Brochard L, Costa EL, Schoenfeld DA, Stewart TE, Briel M, Talmor D, Mercat A, Richard JC, Carvalho CR, Brower RG. Driving pressure and survival in the acute respiratory distress syndrome. N Engl J Med. 2015;372(8):747-55.

34. Famous KR, Delucchi K, Ware LB, Kangelaris KN, Liu KD, Thompson BT. Calfee CS; ARDS Network. Acute Respiratory Distress Syndrome subphenotypes respond differently to randomized fluid management strategy. Am J Respir Crit Care Med. 2017;195(3):331-8.

35. Goligher EC, Amato MBP, Slutsky AS. Applying precision medicine to trial design using physiology. Extracorporeal $\mathrm{CO}_{2}$ removal for acute respiratory distress syndrome. Am J Respir Crit Care Med. 2017;196(5):558-68.

\section{Ready to submit your research? Choose BMC and benefit from:}

- fast, convenient online submission

- thorough peer review by experienced researchers in your field

- rapid publication on acceptance

- support for research data, including large and complex data types

- gold Open Access which fosters wider collaboration and increased citations - maximum visibility for your research: over $100 \mathrm{M}$ website views per year

At BMC, research is always in progress.

Learn more biomedcentral.com/submissions 